\title{
Green Approach to Corrosion Inhibition of Carbon Steel by Fucus spiralis extract in 1 M HCl Medium
}

\author{
Moha Afrokh ${ }^{1,2}$, Said Baroud ${ }^{2}$, Younes Kerroum ${ }^{1}$, Abdelhakim Hatimi ${ }^{2}$, Saida Tahrouch ${ }^{2}$, \\ Issam Sadki 2, Ismail Warad ${ }^{3}$, Abdallah Guenbour ${ }^{1}$, Abdelkbir Bellaouchou 1, Mohamed Tabyaoui ${ }^{1}$, \\ Abdelkader Zarrouk ${ }^{1, *(1)}$ \\ 1 Laboratory of Materials, Nanotechnology and Environment, Faculty of Sciences, Mohammed V University in Rabat, P.O. \\ Box. 1014 Agdal-Rabat, Morocco \\ 2 Laboratory of Plant Biotechnology, Faculty of Sciences, University of Ibn Zohr B.P. 8106, Agadir, Morocco \\ 3 Department of Chemistry and Earth Sciences, PO Box 2713, Qatar University, Doha, Qatar \\ * Correspondence: azarrouk@gmail.com (A.Z.);
}

Scopus Author ID 36125763200

Received: 23.09.2021; Revised: 25.10.2021; Accepted: 28.10.2021; Published: 21.11.2021

\begin{abstract}
The extract of Fucus spiralis (FS) was tested as a corrosion inhibitor of carbon steel in a 1M $\mathrm{HCl}$ medium. The anti-corrosion properties were analyzed by gravimetric and electrochemical techniques such as potentiodynamic polarization (PDP) and electrochemical impedance spectroscopy (EIS). The surface characterization of carbon steel submerged in the optimal solution was carried out using UV-Visible, UV-Vis-NIR, and Optical microscopy analyses. Electrochemical and gravimetric results demonstrated that inhibitory efficiencies increase with increasing inhibitor concentration and the efficiency reaches $87 \%$ at a concentration of $0.5 \mathrm{~g} / \mathrm{L}$. According to Tafel extrapolated polarisation measurements, the FS also worked as a mixed-type corrosion inhibitor and changed the mechanism of anodic reactions. EIS analysis showed that a depressed capacitive loop dominates the Nyquist plot of impedance and enhances the polarization resistance (Rp) to $161.9 \Omega \mathrm{cm}^{2}$ with a reduction of the double layer capacity $(\mathrm{Cdl})$ of carbon steel to $61.8 \mu \mathrm{F} / \mathrm{cm}^{2}$. This protection is assured by an adsorption mechanism based on the isothermal Langmuir adsorption model, which positively affects the thermodynamic parameters. UV-Visible, UV-Vis-NIR analyses exhibited that inhibitor decreases the iron oxides like hematite, Magnetite, and Goethite, Maghemite, Lepidocrocite, $\delta$-FeOOH of the metal surface and delays the dissolution of the bare metal of iron to the ferrous ions, notably that optical morphology showed that FS extract decreases the aggressivity of $\mathrm{HCl}$.
\end{abstract}

Keywords: green inhibitor; carbon steel corrosion; electrochemical techniques; UV-Visible/UV-VisNIR; optical microscopy.

(C) 2021 by the authors. This article is an open-access article distributed under the terms and conditions of the Creative Commons Attribution (CC BY) license (https://creativecommons.org/licenses/by/4.0/).

\section{Introduction}

Carbon steel is frequently used in building materials, and in the industrial process, contact with the acidic environment can damage the material [1]. The study of steel corrosion has received considerable academic and industrial attention in an acidic environment [2-4]. Acid solutions are extensively employed in manufacturing processes like cleaning, descaling, pickling, and acidifying oil wells [5]. Over the past decade, to protect the steel from degradation and prolong its life, corrosion inhibitors have been considered the practical corrosion protection methods, notably in acidic solutions to prevent metal dissolution [6,7]. Thus, several organic chemical compounds were inspected. The researchers suggested that the electronegative property of the $\mathrm{O}, \mathrm{N}, \mathrm{S}$, and $\mathrm{P}$ atoms and the properties of aromatic and unsaturated bonds are 
responsible for inhibition effectiveness. Usually, this inhibitory performance is due to the adsorbent layer that forms on the metal due to the reaction between molecules of organic compounds and the unoccupied orbital of surface metal atoms [8-10]. Currently, due to a factor of toxicity to users and the environment, certain synthetic corrosion inhibitors are abandoned [11]. For that, researchers are interested in using essential oils and medicinal plant extracts as corrosion inhibitors [12,13]. Abdallah et al. [14] were related the inhibiting impact of some plants such as curcumin, parsley, and cassia bark extracts to the molecular size of the major component. The author has also studied the Nutmeg oil as a safe and green inhibitor for the corrosion of carbon steel type L-52 (CS L-52) in $1.0 \mathrm{M} \mathrm{HCl}$, which was explained that the adsorption of nutmeg oil onto the surface of the CS follows the Langmuir isotherm [15].

In addition, the extract of Fucus spiralis (FS) has not been studied before, for that, the curiosity to know the behavior of the carbon steel in the presence of this extract leads us to publish this research document to explain the protection against corrosion of carbon steel in hydrochloric acid ( $\mathrm{HCl} 1 \mathrm{M})$, via a methanolic extract of Fucus spiralis (FS) through different procedures: mass loss, potentiodynamic polarization, electrochemical impedance spectroscopy (EIS), UV-Vis -NIR spectroscopy and optical microscopy technique.

\section{Materials and Methods}

\subsection{Extraction of inhibitor.}

Fucus spiralis (FS) is a type of alga that has a brown color, the origin of this species is the coastal area of Cape Ghir, $43 \mathrm{~km}$ northwest of Agadir (Morocco), which was collected at low tide. This alga is carefully rinsed and dehydrated to eliminate all traces of salt. Then, it is degraded to fine particles using an electric grinder. After that, $20 \mathrm{~g}$ of powder was extracted for 3 hours by the methanol utilizing Soxhlet. The collected extract was concentrated by rotary evaporation, and the efficiency of the final product was about $13.25 \%$.

\subsection{Materials.}

Carbon steel was used in this study with a chemical composition of $0.370 \% \mathrm{C}, 0.230 \%$ $\mathrm{Si}, 0.680 \% \mathrm{Mn}, 0.016 \% \mathrm{~S}, 0.077 \% \mathrm{Cr}, 0.011 \% \mathrm{Ti}, 0.059 \% \mathrm{Ni}, 0.009 \% \mathrm{Co}, 0.160 \% \mathrm{Cu}$ and the rest is iron balanced. The samples are prepared before immersion in the solutions by an abrasive polishing paper with fine particles (220 to 1200), then cleaned by distilled water, followed by a stream of hot air.

\subsection{Preparation of the solutions.}

Simulation of the aggressive environment was obtained using a hydrochloric acid solution $(1 \mathrm{M} \mathrm{HCl})$ from analytical grade $(37 \% \mathrm{HCl})$. The corrosive medium of $1 \mathrm{M}$ hydrochloric acid was chosen because hydrochloric acid is a commonly used mineral for acid cleaning and descaling. The inhibitor used in our study is the methanolic extract of FS. The range of inhibitor concentrations varied from $5 \times 10^{-2} \mathrm{~g} / \mathrm{L}$ to $0.5 \mathrm{~g} / \mathrm{L}$.

\subsection{Gravimetric measurements.}

In these measurements, we prepared the samples in closed glass vials containing $50 \mathrm{~mL}$ of the electrolyte by changing the concentrations of FS extract, the temperature of the test 
solution was $303 \mathrm{~K}$, and the immersion time was 6 hours. The experiments were achieved three times, and the average value of the mass loss was noted.

\subsection{Electrochemical measurements.}

The results of the electrochemical methods were measured employing three electrodes, saturated calomel electrode (SCE), platinum electrode, and carbon steel electrode $\left(1 \mathrm{~cm}^{2}\right)$. The corrosion cell is linked to the VoltaLabpotentiostat (PGZ 100), controlled by the VoltaMaster 4 software. To achieve the stable state of the electrode/solution system, the working electrode is submerged for $30 \mathrm{~min}$ in the solution at open circuit potential ( $\mathrm{E}_{\text {ocp }}$ ). Then, the electrochemical impedance spectroscopy (EIS) results were executed by decreasing the frequency from $100 \mathrm{kHz}$ to $10 \mathrm{mHz}$, with 10 points per decade, and the experiments were repeated three times. After the AC impedance test, the potentiodynamic polarization curve was drawn at the scan rate of $0.5 \mathrm{mV} / \mathrm{s}$, from $-800 \mathrm{mV} / \mathrm{SCE}$ to $-200 \mathrm{mV} / \mathrm{SCE}$.

\subsection{Surface morphology and chemical composition.}

The surface morphology of the samples was obtained by optical microscopy (Leica DM6000 M), and the surface reflectance spectra of the samples were achieved by UV-Vis diffuse reflectance spectroscopy at room temperature using UV-Vis-NIR spectrophotometer (Jasco V670 model), linked to the integrating sphere (ILN-925 model). And the absorbance spectra of the solutions were acquired at room temperature using a UV-Vis spectrophotometer (Jasco V-730 model). These techniques make it possible to identify the presence of the chemical elements that compose the $\mathrm{C}$ - steel in the solution and on the metal surface to assess the degree of corrosion. Optical microscopy (OM) was used to examine the immersion corrosion of carbon steel specimens in acidic solutions with and without inhibitors. The samples were sent to $\mathrm{OM}$ studies after the corrosion testing to determine the surface morphology.

\section{Results and Discussion}

\subsection{Gravimetric measurements.}

The influences of adding algae extract (FS) on the corrosion protection of carbon steel in $1 \mathrm{M} \mathrm{HCl}$ solution were obtained by the mass loss method at $303 \mathrm{~K}$ after 6 hours of immersion. The corrosion rate (V) plus the inhibition efficiency IE(\%) were measured by equations 1 and 2[16-19]:

$$
\begin{aligned}
& v=\frac{\Delta m}{S \times t} \\
& I E(\%)=\frac{v^{0}-v}{v^{0}} \times 100
\end{aligned}
$$

where, $\Delta \mathrm{m}$ is the mass loss (mg), $\mathrm{t}$ is the immersion time (hours), $\mathrm{S}$ is the sample area $\left(\mathrm{cm}^{2}\right)$, where $v^{0}$ is the corrosion rate in the hydrochloric acid solution $(1 \mathrm{M} \mathrm{HCl})$, and $v$ is the corrosion rate in the hydrochloric acid solution $(1 \mathrm{M} \mathrm{HCl})$ with the inhibitor $\left(\mathrm{mg} \mathrm{cm}^{-2} \mathrm{~h}^{-1}\right)$.

The results reached are presented in Table 1. The efficiency increases up to $86 \%$ at 0.50 $\mathrm{g} / \mathrm{L}$. Moreover, the results reveal that improving the concentration of the FS extract decreases 
the corrosion rate values. This decrease may be related to the characterization of the inhibitor, which affects the activity of the metal surface.

Table 1. The corrosion rate of metal and inhibition efficiency of FS extract in $1 \mathrm{M} \mathrm{HCl}$ at $303 \mathrm{~K}$.

\begin{tabular}{l|l|l|l|l|l}
$\mathrm{C}(\mathrm{g} / \mathrm{L})$ & 0 & 0.05 & 0.1 & 0.3 & 0.5 \\
\hline$\nu\left(\mathrm{mg} \mathrm{cm}^{-2} \mathrm{~h}^{-1}\right)$ & 2.40 & 0.96 & 0.72 & 0.47 & 0.34 \\
\hline $\mathrm{IE}(\%)$ & ---- & 60 & 70 & 80 & 86 \\
\hline$\theta$ & ----- & 0.60 & 0.70 & 0.80 & 0.86
\end{tabular}

According to the literature [20], the formation of corrosion products such as rust on the metal surface can improve the corrosion process. In addition to this, the presence of aggressive ions like $\mathrm{Cl}^{-}$also accelerates the corrosion rate of the metal. Still, the use of this inhibitor makes it possible to decrease the destructive attack of this ion. In addition, the results obtained indicate that the mobilization of the inhibiting constituents towards the metal surface decreases the corrosion process, which may alter the formation of corrosion products. This effect can be explained by different approaches. The chemical species that form the SF extract can cover the metal surface, blocking the cathodic and anodic reactions or depreciating the chemical species' reduction and oxidation [21]. Concerning the inhibition efficiency, several kinds of research on green corrosion inhibitors from plant extract have been reported $94.8 \%$ at $10 \mathrm{~g} / \mathrm{L}$ for Xanthium strumarium extract [22], $88 \%$ at $0.8 \mathrm{~g} / \mathrm{L}$ for Glycyrrhiza glabra leaves extract [23], and $98 \%$ at $0.4 \mathrm{~g} / \mathrm{L}$ for Sunflower seed hull extract [24]. Considering the result of this study, the inhibition efficiency of $86 \%$ at $0.5 \mathrm{~g} / \mathrm{L}$ may favor the use of this extract as a corrosion inhibitor.

\subsection{Potentiodynamic polarization measurements.}

The FS extract was used to investigate its effect on the electrochemical behavior of carbon steel in $1 \mathrm{M} \mathrm{HCl}$ solution at $303 \mathrm{~K}$ by the potentiodynamic polarization measurements, as shown in Figure 1.

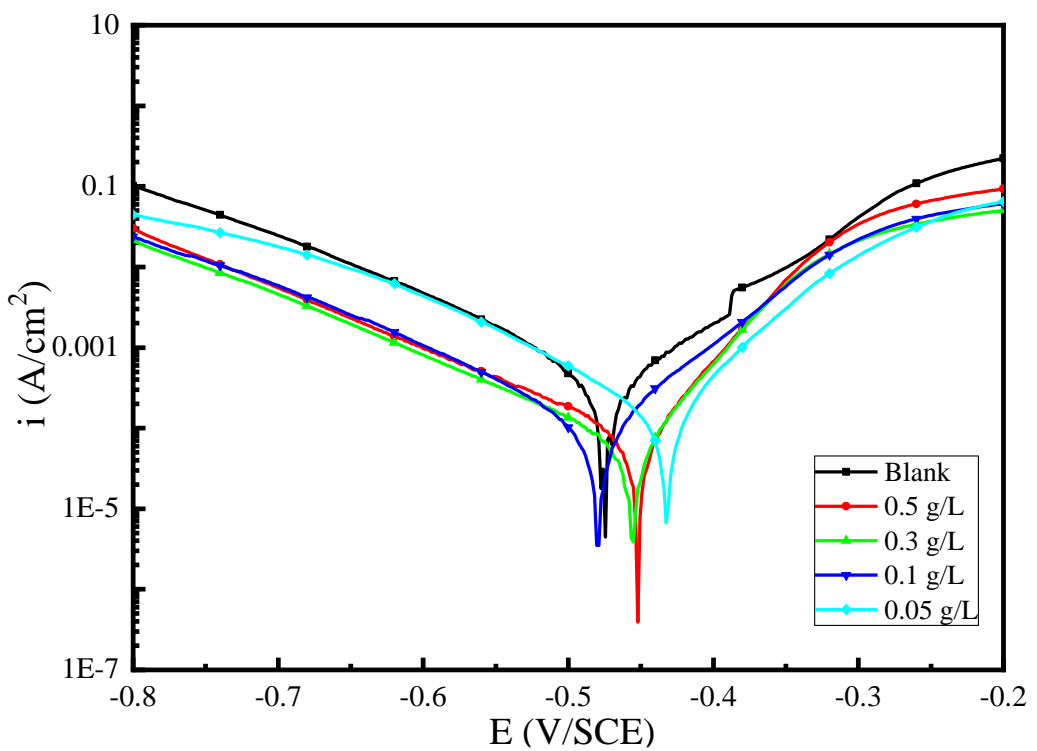

Figure 1. The effect of FS extract on the electrochemical behavior of carbon steel in $1 \mathrm{M} \mathrm{HCl}$ solution at $303 \mathrm{~K}$.

The kinetic parameters, in particular the corrosion current density ( $\left.\mathrm{i}_{\text {corr }}\right)$, the cathodic and anodic slopes of Tafel $\left(\beta_{\mathrm{c}}, \beta_{\mathrm{a}}\right)$, as well as the corrosion potential ( $\left.\mathrm{E}_{\text {corr }}\right)$ are summarized in Table 2. $i_{\text {corr }}$ values are determined by Tafel extrapolation and are exploited to estimate the efficiency of inhibition $\mathrm{IE}_{\text {Tafel }}(\%)$ (Equation 3)[25-27]: 


$$
I E_{\text {Tafel }}(\%)=\frac{i_{\text {corr }}^{0}-i_{\text {corr }}}{i_{\text {corr }}^{0}} \times 100
$$

where, $i_{\text {corr }}^{0}$ is the corrosion current density in the hydrochloric acid solution $(1 \mathrm{M} \mathrm{HCl})$, and $i_{\text {corr }}$ is the corrosion current density in the hydrochloric acid solution $(1 \mathrm{M} \mathrm{HCl})$ with the inhibitor.

Table 2. Electrochemical parameters and corrosion inhibition efficiency of carbon steel in $1 \mathrm{M} \mathrm{HCl}$, without and with the addition of different concentrations of SF extract at $303 \mathrm{~K}$.

\begin{tabular}{l|l|l|l|l|l}
$\begin{array}{l}\text { Conc. } \\
(\mathrm{g} / \mathrm{L})\end{array}$ & $\begin{array}{l}-\mathrm{E}_{\text {corr }} \\
(\mathrm{mV} / \mathrm{SCE})\end{array}$ & $\begin{array}{l}\mathrm{i}_{\text {corr }} \\
\left(\mu \mathrm{A} / \mathrm{cm}^{2}\right)\end{array}$ & $\begin{array}{l}\beta_{\mathrm{a}} \\
(\mathrm{mV} / \mathrm{dec})\end{array}$ & $\begin{array}{l}-\beta_{\mathrm{c}} \\
(\mathrm{mV} / \mathrm{dec})\end{array}$ & $\mathrm{IE}_{\text {Tafel }}(\%)$ \\
\hline 0.0 & 477 & 430.9 & 111.0 & 118.6 & - \\
\hline 0.5 & 455 & 58.9 & 49.0 & 108.3 & 86 \\
\hline 0.3 & 458 & 65.0 & 53.0 & 131.9 & 85 \\
\hline 0.1 & 483 & 99.4 & 76.2 & 115.0 & 77 \\
\hline 0.05 & 435 & 135.1 & 60.8 & 106.2 & 69
\end{tabular}

Besides, the current density decreases with increasing concentration (Table 2), which confirms the creation of a protective layer that preserved the metal surface [28]. This appeared on the inhibition efficiency, which reached the percentage of $86 \%$, close to the value of the gravimetric measurements. Furthermore, the cathodic and anodic slopes of Tafel $\left(\beta_{c}, \beta_{\mathrm{a}}\right)$ are changed with the addition of FS extract. In general, the Tafel slope value of the anode is more changed and significantly decreased, which is evidence that the oxidation reaction mechanism of iron is influenced. On the other hand, The Tafel slope value of the cathode is not more changed and stayed at the value of about $120 \mathrm{mV}$, which means that the compounds responsible for inhibition are not changed the mechanism of cathodic hydrogen evolution, which occurs for one electron in the charge transfer controlled reaction [29], and rather the adsorbed compounds block the active sites [30].

Therefore, the $\mathrm{E}_{\mathrm{corr}}$ values are slightly shifted towards the anodic potential. According to the literature [31-34], the inhibitor can recognize it as an anodic inhibitor, cathodic inhibitor, or mixed inhibitor, depending on the variation of the corrosion potential. Therefore, in our case, the FS extract behaves like a mixed inhibitor since this change does not exceed $\pm 85 \mathrm{mV}$.

\subsection{Electrochemical impedance spectroscopy (EIS).}

The carbon steel impedance spectra in $1 \mathrm{M} \mathrm{HCl}$ using different concentrations of FS extract are presented as Nyquist curves (Figure 2). Nyquist diagrams contain incomplete halfcircles representing the capacitive loop and having a center below the real axis.

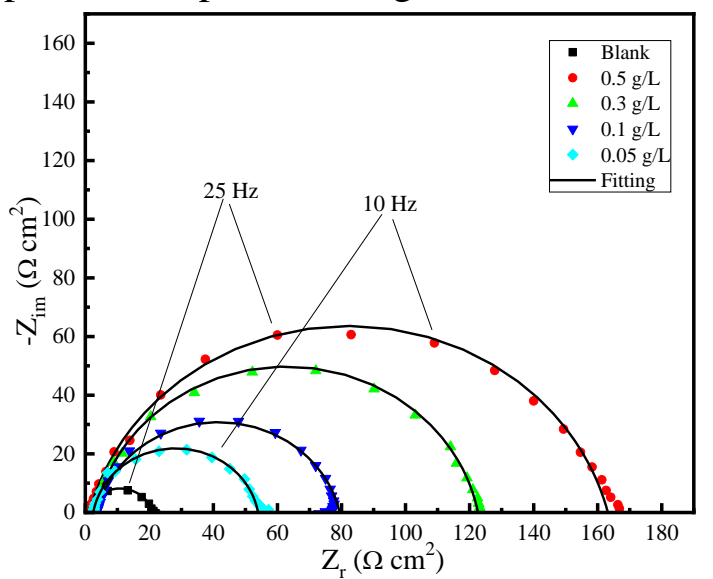

Figure 2. Carbon steel impedance spectra in $1 \mathrm{M} \mathrm{HCl}$ solution, with modification of FS extract concentrations at $303 \mathrm{~K}$. 
The EIS results are generated by software through the electrical circuit illustrated in Figure 3 to model the studied electrochemical system and estimate numerical values matching the properties of the system[35,36]. In the equivalent electrical circuit, $R_{\mathrm{s}}$ is the resistance of the solution, $R_{p}$ is the polarization resistance, and CPE represents the constant phase element that models the imperfect of the double layer.

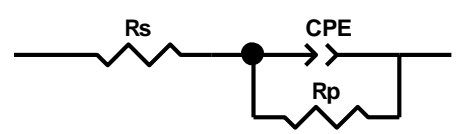

Figure 3. Simulated carbon steel/electrolyte system using this electrical circuit.

The impedance behavior of CPE is calculated by this function [30,37]:

$$
Z_{C P E}=\frac{1}{Y_{0} \times(j \times \omega)^{n}}
$$

$\omega$ is the angular frequency, $n$ and $Y_{o}$ represent the phase shift and the magnitude of CPE, respectively.

And the double layer capacitance is measured via the CPE magnitude and the polarization resistance $R_{p}$, and the phase shift $n$ (Equation 5) [30,37] :

$$
C_{d l}=\left[Y_{0}^{1 / n} \times\left(R_{p}\right)^{\frac{1-n}{n}}\right]
$$

The following equation 6 represents the relation between the inhibition efficiency and the polarization resistance values [38-40]:

$$
I E_{R_{p}}(\%)=\frac{R_{p}-R_{p}^{0}}{R_{p}} \times 100
$$

where, $R_{p}^{0}$ and $R_{p}$ are the polarization resistance in the non-attendance and the attendance of the inhibitor, respectively. The values of the extracted impedance components are registered in Table 3.

\begin{tabular}{|c|c|c|c|c|c|c|}
\hline $\begin{array}{l}\text { Conc. } \\
(\mathrm{g} / \mathrm{L})\end{array}$ & $\begin{array}{l}\mathbf{R}_{\mathbf{s}} \\
\left(\mathbf{\Omega} \mathrm{cm}^{2}\right)\end{array}$ & $\begin{array}{l}Y_{0}\left(\times 10^{4}\right) \\
\left(\Omega^{-1} \mathbf{s}^{\mathbf{n}} \mathbf{c m}^{-2}\right) \\
\end{array}$ & $\mathbf{n}$ & $\begin{array}{l}\mathbf{R}_{\mathbf{p}} \\
\left(\boldsymbol{\Omega} \mathbf{~ c m}^{2}\right)\end{array}$ & $\begin{array}{l}\mathrm{C}_{\mathrm{dl}} \\
\left(\mu \mathrm{F} / \mathrm{cm}^{2}\right)\end{array}$ & $I E_{R_{p}}(\%)$ \\
\hline blank & 0.58 & 4.59 & 0.864 & 20.3 & 221.1 & - \\
\hline 0.5 & 1.27 & 1.24 & 0.848 & 161.9 & \begin{tabular}{ll|}
61.8 \\
\end{tabular} & 87 \\
\hline 0.3 & 3.10 & 1.21 & 0.884 & 119.5 & 69.7 & 82 \\
\hline 0.1 & 3.57 & 1.35 & 0.869 & 75.8 & 68.1 & 72 \\
\hline 0.05 & 2.49 & 2.69 & 0.897 & 51.4 & 165.1 & 61 \\
\hline
\end{tabular}

Table 3. Values of the extracted impedance components in $1 \mathrm{M} \mathrm{HCl}$ solution, with modification of FS extract concentrations at $303 \mathrm{~K}$.

According to the results obtained (Table 3), it is observed that the concentrations of FS extract are proportional to the inhibition efficiency implies that the extract serves to protect the metal surface [2]. This protection is generally enhanced with the (n) parameter that reflects the inhomogeneity of the surface, which means that the metal surface is relatively homogeneous in the presence of FS extract compared to without it. This modification may reinforce the polarization resistance $R_{p}$ values and decreases the bilayer capacitance $C_{d l}$. But the proportionality doesn't verify, which suggests that other parameters influence the polarization resistance $R_{p}$ and the bilayer capacitance $C_{d l}$. Furthermore, the polarization resistance $R_{p}$ rises 
from $20.3 \Omega \mathrm{cm}^{2}$ to $161.9 \Omega \mathrm{cm}^{2}$ and the bilayer capacitance $C_{\mathrm{dl}}$ decreases from $221.1 \mu \mathrm{F} / \mathrm{cm}^{2}$ to $61.8 \mu \mathrm{F} / \mathrm{cm}^{2}$, the variation of this value can be associated with the thickness evolution of the electrical double-layer [41], which is consistent with the Helmholtz model, assumed through the following equation 7 [42]:

$$
C_{d l}=\frac{\varepsilon_{0} \varepsilon}{d} S
$$

where $\varepsilon_{0}$ denotes the permittivity in a vacuum, $\varepsilon$ is the permittivity, $\mathrm{d}$ denotes film thickness, and $\mathrm{S}$ denotes surface area. From this relation, it is clear that the protection of the metal surface may be due to a decrease in the permittivity or an increase of the FS compounds thickness that adsorbed on the metal surface.

\subsection{Temperature effect.}

The estimated effect of temperature on the FS extract inhibition and the activation parameters of the metal applying the polarization measurements are studied in the presence of the inhibitor $(0.5 \mathrm{~g} / \mathrm{L})$ and the range temperature $303 \mathrm{~K}-333 \mathrm{~K}$ (Figure 4).
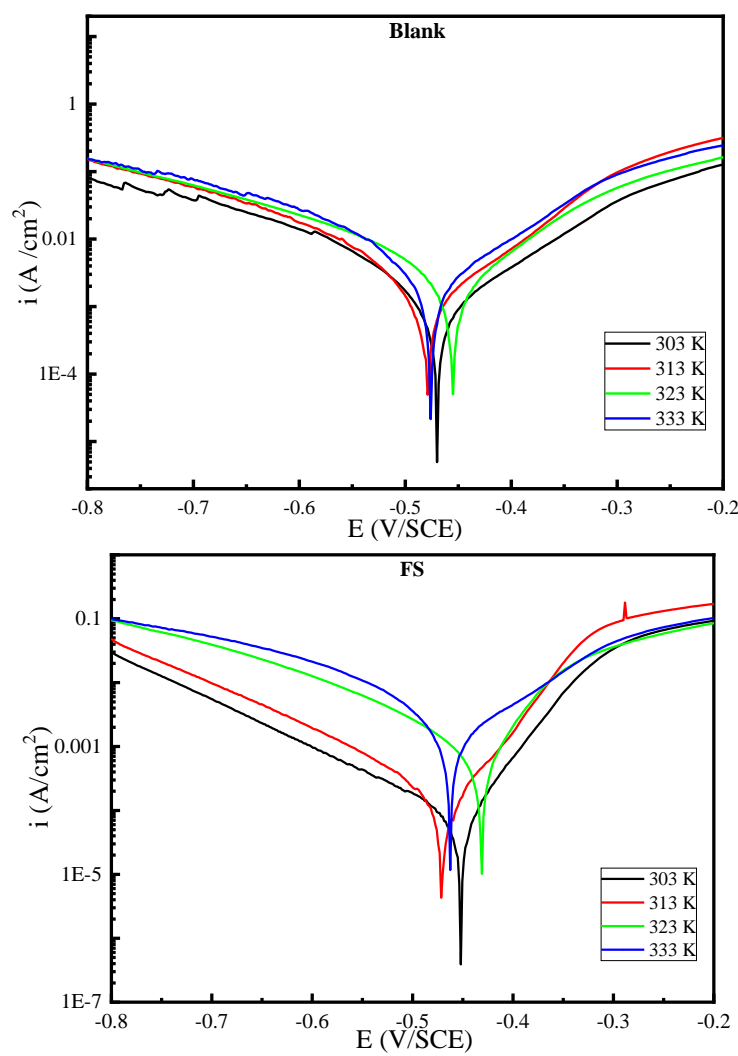

Figure 4. The effect of temperature on the electrochemical behavior of the metal in $1 \mathrm{M} \mathrm{HCl}+0.50 \mathrm{~g} / \mathrm{L}$ of FS extract.

Table 4. The effect of temperature on the electrochemical parameters of the metal in $1 \mathrm{M} \mathrm{HCl}+0.50 \mathrm{~g} / \mathrm{L}$ of FS extract.

\begin{tabular}{|c|c|c|c|c|c|c|}
\hline & $\begin{array}{l}\mathbf{T} \\
(\mathbf{K})\end{array}$ & $\begin{array}{l}-\mathbf{E}_{\mathrm{corr}} \\
(\mathrm{mV} / \mathrm{SCE})\end{array}$ & $\begin{array}{l}\mathbf{i}_{\text {corr }} \\
\left(\mathbf{m A} / \mathrm{cm}^{2}\right)\end{array}$ & $\begin{array}{l}\beta_{\mathrm{a}} \\
(\mathrm{mV} / \mathrm{dec})\end{array}$ & $\begin{array}{l}-\beta_{\mathrm{c}} \\
(\mathrm{mV} / \mathrm{dec})\end{array}$ & $\operatorname{IE}_{\text {Tafel }}(\%)$ \\
\hline \multirow{4}{*}{ Blank } & 303 & 477 & 0.430 & 111.0 & 118.6 & - \\
\hline & 313 & 482 & 0.966 & 91.0 & 73.8 & - \\
\hline & 323 & 458 & 1.509 & 87.2 & 87.6 & - \\
\hline & 333 & 480 & 1.966 & $\begin{array}{l}110.9 \\
\end{array}$ & 94.1 & - \\
\hline \multirow{4}{*}{ FS } & 303 & 455 & 0.058 & 49.0 & 108.3 & 86 \\
\hline & 313 & 473 & 0.149 & 69.3 & $\begin{array}{l}108.8 \\
\end{array}$ & 85 \\
\hline & 323 & 434 & 0.778 & 60.4 & 126.8 & 60 \\
\hline & 333 & 465 & 1.122 & 102.9 & 75.1 & 43 \\
\hline
\end{tabular}


Analysis of the results grouped in Table 4 unveils that an augment in temperature improves the corrosion current density of the metal. But the effect is less in the presence of FS extract, which decreases the inhibition efficiency. This comportment may be elucidated through the desorption of FS extract molecules at higher temperatures due to weak interactions between the metal surface and the molecules responsible for the inhibition [43].

For the thermodynamic activation parameters, the corrosion rate as a function of temperature was studied, first using the Arrhenius equation 8 [44]:

$$
i_{\text {corr }}=k \times \exp \left(\frac{-E_{a}}{R \times T}\right)
$$

$\mathrm{i}_{\text {corr }}$ is the density of the corrosion current, $\mathrm{K}$ is a pre-exponential factor, $\mathrm{E}_{\mathrm{a}}$ is the activation energy and, $\mathrm{R}$ is the perfect gas constant, $\mathrm{T}$ is the absolute temperature.

Figure 5 illustrates the modification of the corrosion current density by the inverse of the temperature. Without and with inhibitor, this variation represents a straight line, and from the Arrhenius relation, we can calculate the activation energy.

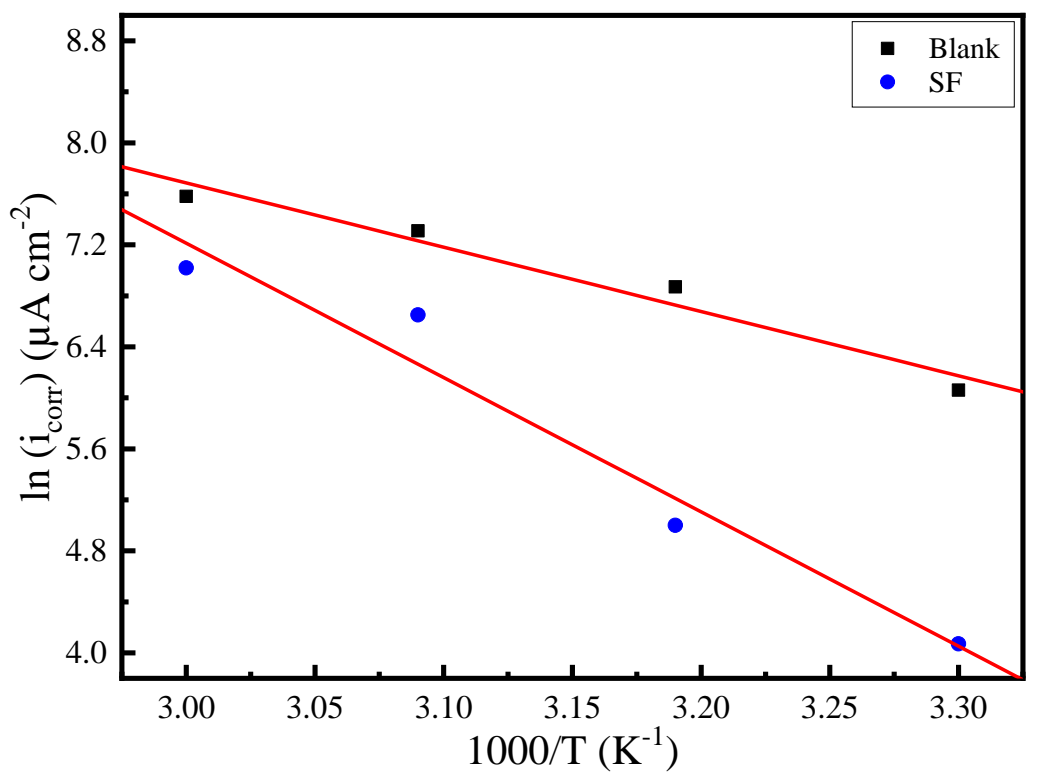

Figure 5. Modifications of Arrhenius curves for C-steel, without (Blank) and with $0.50 \mathrm{~g} / \mathrm{L}$ of FS extract in 1 $\mathrm{M} \mathrm{HCl}$.

Moreover, to understand the adsorption mechanism, the thermodynamic parameters of the dissolution of carbon steel in $1 \mathrm{M} \mathrm{HCl}$ are examined without and with an optimal concentration of FS extract (Figure 6). In this regard, the transition state equation is used applying equation 9 [45-47]:

$$
i_{\text {corr }}=\frac{R \times T}{N \times h} \times \exp \left(\frac{\Delta S_{a}}{R}\right) \exp \left(\frac{-\Delta H_{a}}{R \times T}\right)
$$

h: Plank constant, $\mathrm{N}$ : Avogadro number, $\Delta H_{a}$ Activation enthalpy, and $\Delta S_{a}$ : Activation entropy.

The variation of $\ln \left(\mathrm{i}_{\mathrm{corr}} / \mathrm{T}\right)$ as a function of the inverse of the temperature $1 / \mathrm{T}$ is a straight line (Figure7), with a slope equal to $\left(-\Delta H_{a} / \mathrm{R}\right)$ and ordinate at the origin equal to (ln $\left.\mathrm{R} / \mathrm{Nh}+\Delta S_{a} / \mathrm{R}\right)$. These parameters have been calculated and listed in Table 5. 


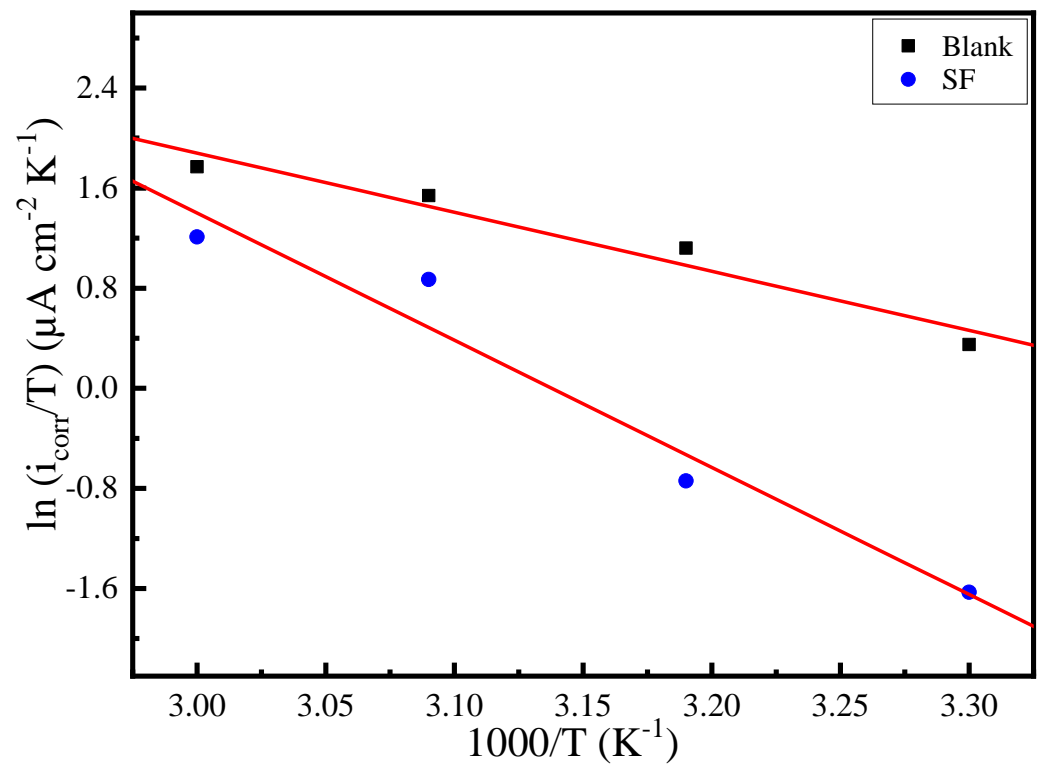

Figure 6. Modification of the transition state curves for C-steel, without (Blank) and with $0.50 \mathrm{~g} / \mathrm{L}$ of FS extract in $1 \mathrm{M} \mathrm{HCl}$.

Table 5. Activation energies, enthalpies, and entropy values for $\mathrm{C}$ - steel in $1 \mathrm{M} \mathrm{HCl}$ in the absence and the presence of $0.5 \mathrm{~g} / \mathrm{L}$ of the inhibitor.

\begin{tabular}{l|l|l|l} 
Activation parameters & $\begin{array}{l}\mathbf{E}_{\mathbf{a}} \\
(\mathbf{k J} / \mathbf{m o l})\end{array}$ & $\begin{array}{l}\Delta H_{a} \\
(\mathbf{k J} / \mathbf{m o l})\end{array}$ & $\begin{array}{l}\Delta S_{a} \\
(\mathbf{J} / \mathbf{m o l ~ K})\end{array}$ \\
\hline Blank & 41.92 & 39.27 & -64.10 \\
\hline $0.5 \mathrm{~g} / \mathrm{L}$ & 87.54 & 84.47 & 67.59
\end{tabular}

Moreover, Table 5 unveiled that the presence of FS extract in the corrosive solution improves the $\mathrm{E}_{\mathrm{a}}$ that means the energy barrier for corrosion reaction is increased, which means the chemical compounds of FS extract enhance the protection of metal surface from the dissolution process. Besides that, the thermodynamic parameter $\Delta H_{a}$ with FS extract is greater $\left(84.47 \mathrm{~kJ} \mathrm{~mol}^{-1}\right)$ than in the absence of inhibitor $\left(39.27 \mathrm{~kJ} \mathrm{~mol}^{-1}\right)$, proposing that the decomposition of steel is delayed in the presence of FS extract [48]. The positive sign $\Delta H_{a}$ reflects the endothermic nature of the dissolution process of steel. The increase in $\Delta S_{a}$ is commonly described as an improvement in disorder caused by the substitution of water molecules by adsorption of FS extract chemicals onto the steel surface[49].

\subsection{Adsorption isotherm.}

The weight loss measurement was used to evaluate the nature of the adsorption of FS inhibitor on the carbon steel surface in $1 \mathrm{M} \mathrm{HCl}$ solution at $303 \mathrm{~K}$. The corrosion inhibition efficiencies $(\eta)$ of the selected method was used to evaluate the surface coverage $(\theta)$ as $\theta=\eta / 100$ (Table 1) in the monolayer adsorption model of Langmuir isotherm expression presented as Eq. (10).

$$
\text { Conc. } / \theta=1 / K_{a d s}+\text { Conc. }
$$

where $\mathrm{K}_{\mathrm{ads}}$ is the adsorption constant and Conc. is the concentration of the corresponding FS on the carbon steel surface.

The plot of the ratio of the FS inhibitor concentration and the surface coverage (Conc./ $\theta$ ) versus concentration (Conc.) were used to generate the Langmuir isotherm curves for the FS inhibitor shown in Figure 7. The adsorption constant $\left(\mathrm{K}_{\mathrm{ads}}\right)$, slope, and other 
Langmuir isotherm parameters are enumerated in Table 6. It can be observed that the slope obtained from the weight loss method for FS is approximately following the monolayer adsorption model proposed in Eq. (10). This can be interpreted that the adsorption of FS inhibitor on the surface of carbon steel in $1 \mathrm{M} \mathrm{HCl}$ solution at $303 \mathrm{~K}$ obeys a monolayer adsorption model. The $\mathrm{K}_{\mathrm{ads}}$ value is attributed to measuring the affinity of an inhibitor to the adsorption site; usually, a high value suggests protection of the metal surface. In our case, the value is less related to the nature of FS extract, which contains numerous chemical compounds, which let difficult to estimate the molar concentration. As electrochemical and gravimetric methods verified the efficacy, we can suggest that FS extract compounds follow Langmuir isotherm with an adsorption interaction with carbon steel.

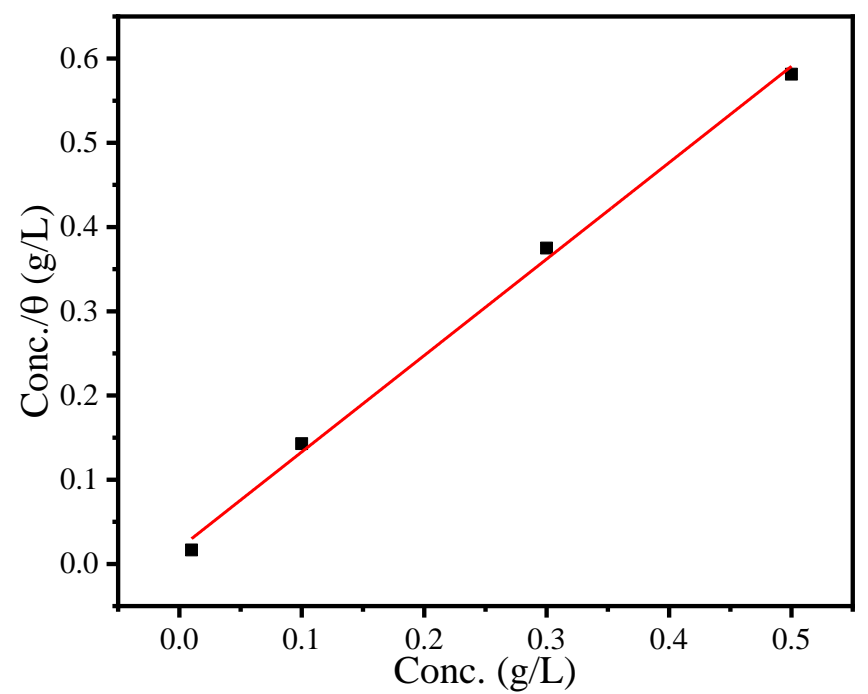

Figure 7. Langmuir isotherm curves of carbon steel surface in $1 \mathrm{M} \mathrm{HCl}$ solution in the absence and presence of different concentrations of FS inhibitor at $303 \mathrm{~K}$.

In order to determine the nature of the interaction, physisorption or chemisorption, between the molecules that compose the FS extract and the metal surface, Gibb's free energy of adsorption $\left(\Delta G_{a d s}^{\circ}\right)$ must be estimated using Eq. (11).

$$
\Delta G_{a d s}^{\circ}=-R \times T \times \operatorname{Ln}\left(C_{\mathrm{H}_{2} \mathrm{O}} \times K_{a d s}\right)
$$

The parameters $R, C_{\mathrm{H} 2 \mathrm{O}}$, and $T$ are universal gas constant, the concentration of pure water in the solution, and temperature $(K)$, respectively $\left(R=8.314 \mathrm{~J} \mathrm{~mol}^{-1} \mathrm{~K}^{-1}\right.$ and $C_{\mathrm{H} 2 \mathrm{O}}=10^{3}$ $\mathrm{g} / \mathrm{L})$. However, it could be mentioned that FS extract weight is not recognized. Thus, $\Delta G_{\text {ads a }}^{0}$ determination is not allowed, which confirms what has been described previously using other plants that have been extracted with different solvent and extraction techniques so that to obtain green corrosion inhibitors [50-53].

Table 6. Langmuir isotherm parameters of carbon steel surface in $1 \mathrm{M} \mathrm{HCl}$ solution in the presence of FS inhibitor at $303 \mathrm{~K}$.

\begin{tabular}{l|l|l|l} 
& $\mathbf{R}^{2}$ & Slope & $\begin{array}{l}\mathbf{K}_{\text {ads }} \\
(\mathbf{L} / \mathbf{g})\end{array}$ \\
\hline FS & 0.998 & 1.12 & 31.14
\end{tabular}

\section{6. $U V-V i s-N I R$ spectroscopy.}

UV-Vis-NIR diffuse reflectance spectroscopy of the surface was analyzed after the 48 hours immersion time at room temperature. As shown in Figure 8, the reflectance of the metal 
surface after immersion in the presence of FS extract shows a percentage of reflectance between that presented by the blank solution and before immersion.

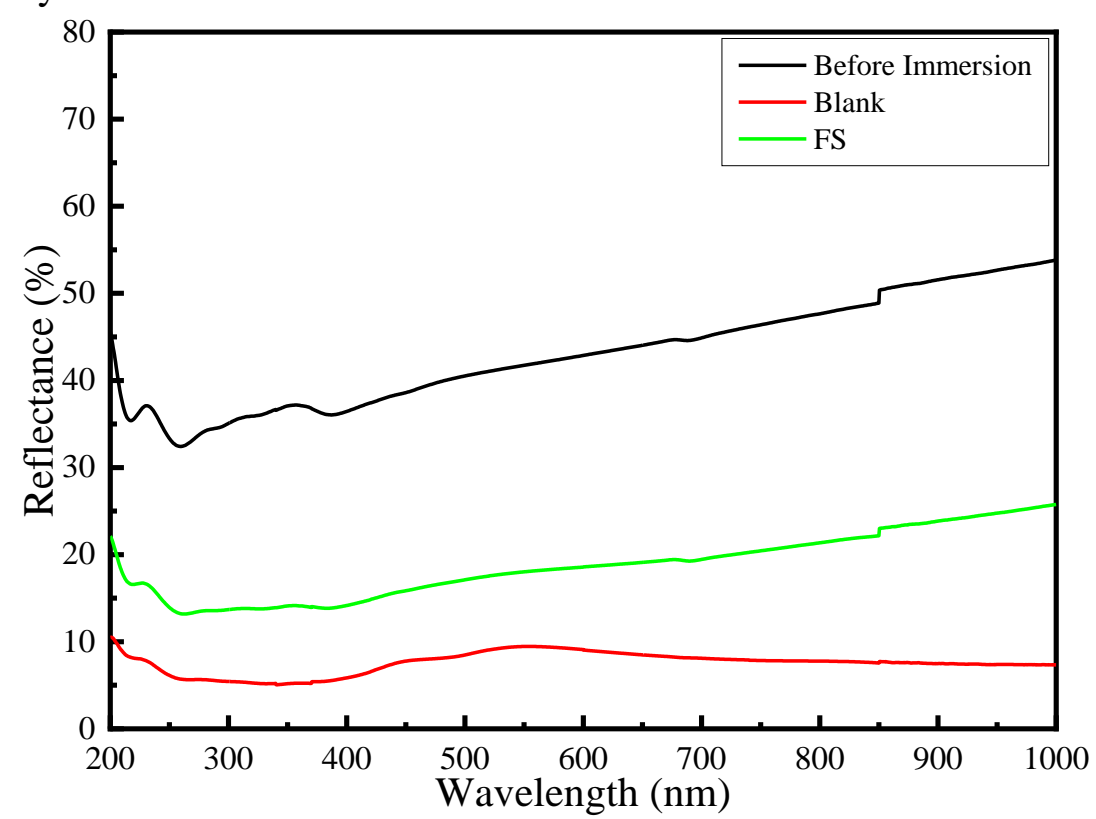

Figure 8. UV-Vis-NIR diffuse reflectance spectroscopy of the surface for C-steel before and after the 48 hours immersion time in $1 \mathrm{M} \mathrm{HCl}$ (Blank) and with $0.50 \mathrm{~g} / \mathrm{L}$ of $\mathrm{FS}$ extract at room temperature.
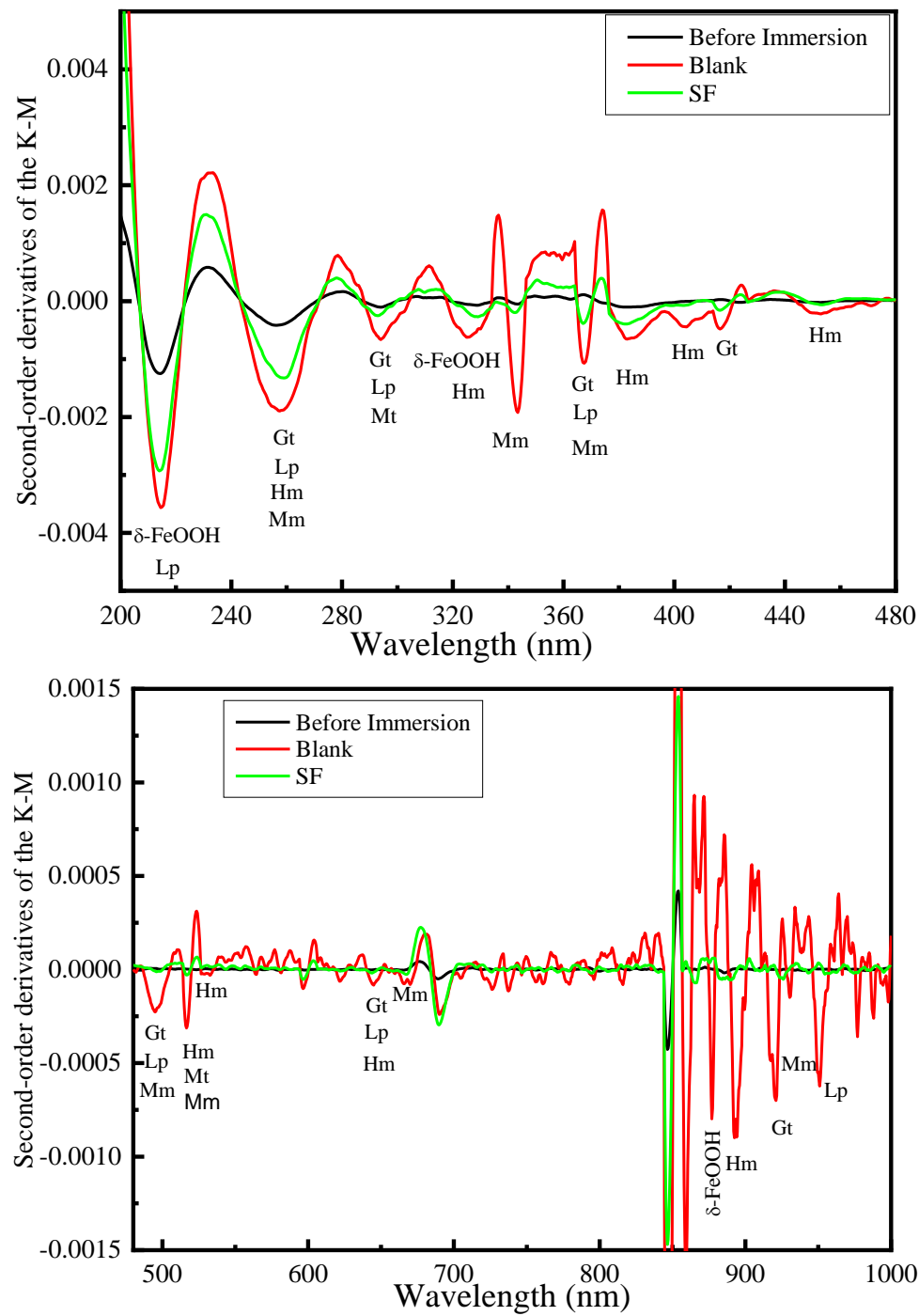

Figure 9. Second derivatives of K-M function spectra of the surface for C-steel before and after the 48 hours immersion time in $1 \mathrm{M} \mathrm{HCl}$ (Blank) and with $0.50 \mathrm{~g} / \mathrm{L}$ of $\mathrm{FS}$ extract at room temperature. 
Furthermore, we also examined the second derivatives of K-M (Kubelka-Munk) function spectra to identify the iron oxides [54]. Figure 9 shows the possibility of detecting the absorption bands corresponding to hematite $(\mathrm{Hm})$, Magnetite $(\mathrm{Mt})$, and Goethite $(\mathrm{Gt})$, Maghemite (Mm), Lepidocrocite (Lp), $\delta$-FeOOH[54-57]. However, These oxides have overlapping bands that are difficult to differentiate.

For this, From the point of view of the degradation of a material, the amplitude between the lowest point and the highest near point of the absorption bands can be accepted as a quantitative parameter to estimate the degree of degradation or protection of material against an aggressive environment $[37,58,59]$. In the case of FS extract, the amplitude of the iron oxides corresponding to the surface of the metal shows an amplitude between that presented by the blank solution and before immersion, which means that the surface was less attacked and protected.

For further interpretation of the inhibition effect, UV-Vis Spectroscopy of the solution was utilized. Figure 10 displays the UV-Vis Spectroscopy of the solution after immersion of the metal for 2 days (48h), the black line corresponds to the $1 \mathrm{M} \mathrm{HCl}$ solution (Blank), and the green line linked to the $1 \mathrm{M} \mathrm{HCl}$ solution with $0.5 \mathrm{~g} / \mathrm{L}$ of the inhibitor (FS).

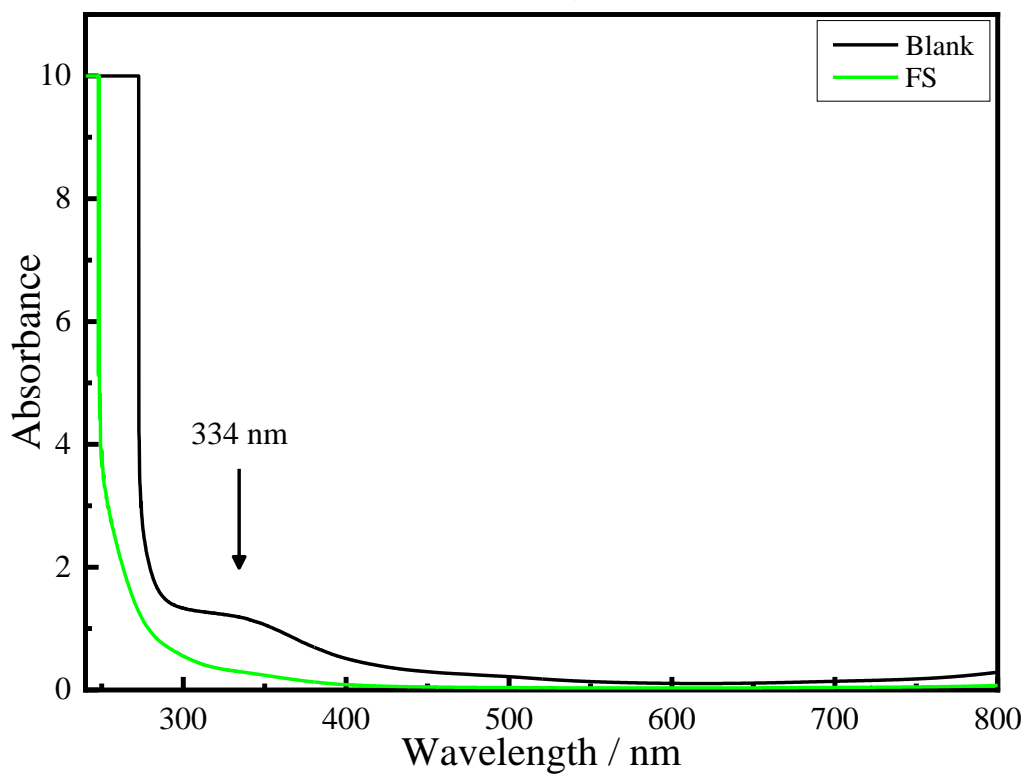

Figure 10. UV-Vis absorption spectroscopy of the $1 \mathrm{M} \mathrm{HCl}$ solution (Blank) and with $0.50 \mathrm{~g} / \mathrm{L}$ of FS extract after 48 hours of immersion time of $\mathrm{C}$-steel at room temperature.

As observed in Figure 10, a peak at $334 \mathrm{~nm}$ is detected in the blank solution, and this band is related to the presence of ferric chloride $\mathrm{FeCl}_{3}$ [60]. Usually, the dissolution of bare iron in the hydrochloric solution is a transformation of $\mathrm{Fe}$ atom into ferrous ions $\mathrm{Fe}^{2+}$, the presence of ferric ions, in this case, can be related to the dissolution of iron oxides that contain ferric ions in their structure (Equation 12-13).

$$
\begin{aligned}
& \mathrm{Fe}_{2} \mathrm{O}_{3(s)}+6 \mathrm{HCl}_{(a q)} \rightarrow 2 \mathrm{FeCl}_{3(a q)}+3 \mathrm{H}_{2} \mathrm{O}_{(L)} \\
& \mathrm{Fe}_{3} \mathrm{O}_{4(s)}+8 \mathrm{HCl}_{(a q)} \rightarrow \mathrm{FeCl}_{2(a q)}+2 \mathrm{FeCl}_{3(a q)}+4 \mathrm{H}_{2} \mathrm{O}_{(L)}
\end{aligned}
$$

In addition, this is confirmed by the previous technique, which is identified the iron oxides that have $\mathrm{Fe}^{3+}$. Another suggestion that can enhance the presence of $\mathrm{FeCl}_{3}$ is the oxidation process of ferrous chloride $\mathrm{FeCl}_{2}$ with oxygen, as demonstrated by the following reaction:

$$
4 \mathrm{FeCl}_{2(a q)}+\mathrm{O}_{2}+4 \mathrm{HCl}_{(a q)} \rightarrow 4 \mathrm{FeCl}_{3(a q)}+2 \mathrm{H}_{2} \mathrm{O}_{(L)}
$$


On the other hand, the absence of this peak is observed in the solution with the inhibitor, it is a sign of the inhibitory effect of the SF extract, which delays the dissolution of the bare metal of iron to the ferrous ions.

\subsection{Optical morphology.}

To confirm the inhibitory effect of the FS extract on the metal, the surface morphology was inspected by optical microscopy after $48 \mathrm{~h}$ of immersion in $1 \mathrm{M} \mathrm{HCl}$ with and without the FS extract (Figure 11). Figure 11-b shows serious damage to the metal surface due to an aggressive environment caused by $\mathrm{Cl}^{-}$ion activity. In contrast, the existence of $0.5 \mathrm{~g} / \mathrm{L}$ of FS attenuates the aggressivity of HCL molecules, as shown in Figure 11-c.
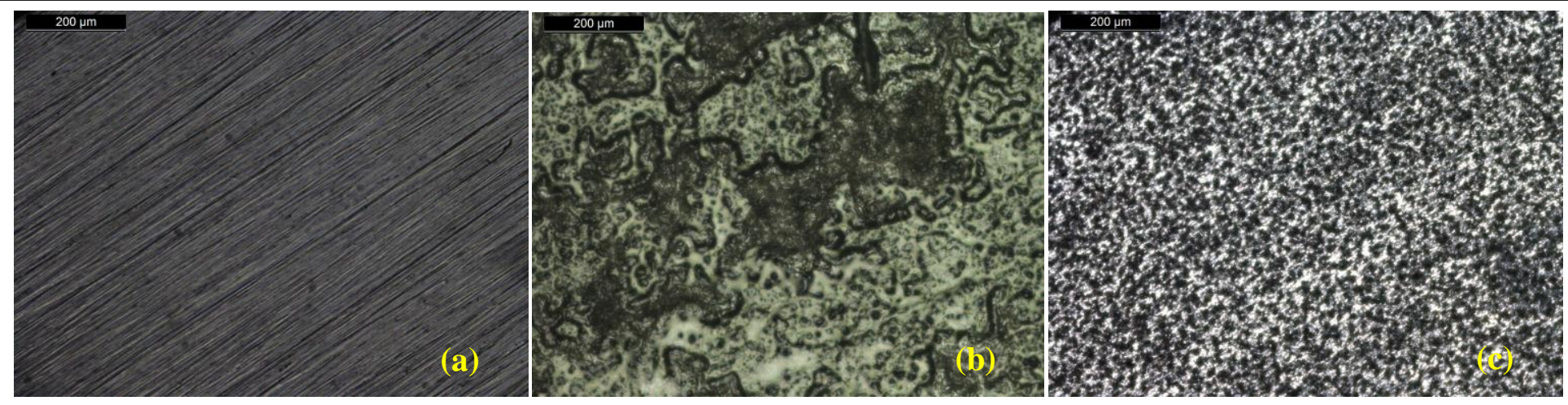

Figure 11. Optical morphology of the carbon steel surface after $48 \mathrm{~h}$ of immersion at room temperature. (a) before immersion, (b) in $1 \mathrm{M} \mathrm{HCl}$, (c) in $1 \mathrm{M} \mathrm{HCl}+0.5 \mathrm{~g} / \mathrm{L}$ of FS.

\section{Conclusions}

In this study, the gravimetric measurements of carbon steel explained that Fucus spiralis (FS) extract is a novel corrosion inhibitor in an aggressive environment of $1 \mathrm{M} \mathrm{HCl}$ at $303 \mathrm{~K}$, with an efficiency of $86 \%$ at $0.5 \mathrm{~g} / \mathrm{L}$. Polarization studies have clarified that the inhibitor acts as a mixed inhibitor which influences the anodic reaction mechanism and just blocks the active cathodic sites. This decreases the corrosion current density and shifts the $\mathrm{E}_{\text {corr }}$ slightly. Moreover, This change was verified by EIS graphs, in which the FS extract improves the resistance of the polarization $\left(\mathrm{R}_{\mathrm{p}}\right)$ and minimizes the double layer capacity $\left(\mathrm{C}_{\mathrm{dl}}\right)$ of carbon steel. Temperature affected the performance of the FS extract due to weak interactions between the metal surface and the chemical substances responsible for the inhibition, assuming that the adsorption is mainly due to the physisorption mechanism. Thermodynamic parameters explained that the FS extract in the aggressive solution enhances the activation energy, retains the endothermic process of the reactions at the metal/solution interface, and increases the level of disorder. Besides that, the adsorption isotherm method showed that FS extract follows Langmuir isotherm. The results acquired were homogeneous with the results obtained by UVVis-NIR spectroscopy, which is shown a decrease of iron oxides of the metal surface and a diminution of iron ions in the solution, especially that optical morphology showed that FS extract attenuates the aggressivity of $\mathrm{HCl}$.

\section{Funding}

This research received no external funding. 


\section{Acknowledgments}

We thank all colleagues.

\section{Conflicts of Interest}

The authors declare no conflict of interest.

\section{References}

1. Deyab, M.A. Effect of cationic surfactant and inorganic anions on the electrochemical behavior of carbon steel in formation water. Corros. Sci. 2007, 49, 2315-2328, https://doi.org/10.1016/j.corsci.2006.10.035.

2. Bentiss, F.; Traisnel, M.; Lagrenee, M. The substituted 1,3,4-oxadiazoles: a new class of corrosion inhibitors of mild steel in acidic media. Corros. Sci. 2000, 42, 127-146, https://doi.org/10.1016/S0010-938X(99)000499.

3. Khaled, K.F. Application of electrochemical frequency modulation for monitoring corrosion and corrosion inhibition of iron by some indole derivatives in molar hydrochloric acid. Mater. Chem. Phys. 2008, 112, 290300, https://doi.org/10.1016/j.matchemphys.2008.05.056.

4. Loto, R.T.; Mbah, E.H.; Ugada, J.I. Corrosion inhibition effect of citrus sinensis essential oil extract on plain carbon steel in dilute acid media. South African J. Chem. Eng. 2020, 0-1, https://doi.org/10.1016/j.sajce.2020.08.004.

5. Machnikova, E.; Whitmire, K.H.; Hackerman, N. Corrosion inhibition of carbon steel in hydrochloric acid by furan derivatives. Electrochim. Acta 2008, 53, 6024-6032, https://doi.org/10.1016/j.electacta.2008.03.021.

6. Ashassi-Sorkhabi, H.; Seifzadeh, D.; Hosseini, M.G. EN, EIS and polarization studies to evaluate the inhibition effect of 3H-phenothiazin-3-one, 7-dimethylamin on mild steel corrosion in $1 \mathrm{M} \mathrm{HCl}$ solution. Corros. Sci. 2008, https://doi.org/10.1016/j.corsci.2008.09.022.

7. Satapathy, A.K.; Gunasekaran, G.; Sahoo, S.C.; Amit, K.; Rodrigues, P. V. Corrosion inhibition by Justicia gendarussa plant extract in hydrochloric acid solution. Corros. Sci. 2009, https://doi.org/10.1016/j.corsci.2009.08.016.

8. Rouifi, Z.; Benhiba, F.; El Faydy, M.; Laabaissi, T.; About, H.; Oudda, H.; Warad, I.; Guenbour, A.; Lakhrissi, B.; Zarrouk A. Performance and computational studies of new soluble triazole as corrosion inhibitor for carbon steel in HCl. Chem. Data Collect. 2019, 22, 100242, https://doi.org/10.1016/j.cdc.2019.100242.

9. Louadi, Y.E.; Abrigach, F.; Bouyanzer, A.; Touzani, R.; El Assyry, A.; Zarrouk, A.; Hammouti, B. Theoretical and Experimental Studies on the Corrosion Inhibition Potentials of Two Tetrakis Pyrazole Derivatives for Mild Steel in 1.0 M HCl. Port. Electrochim. Acta 2017, 35, 59-178, HTTPS://DOI.ORG/10.4152/pea.201703159.

10. Bammou, L.; Belkhaouda, M.; Salghi, R.; Benali, O.; Zarrouk, A.; Zarrok, H.; Hammouti, B. Corrosion inhibition of steel in sulfuric acidic solution by the Chenopodium Ambrosioides Extracts. J. Assoc. Arab Univ. Basic Appl. Sci. 2014, 16, 83-90, https://doi.org/10.1016/j.jaubas.2013.11.001.

11. Ostovari, A.; Hoseinieh, S.M.; Peikari, M.; Shadizadeh, S.R.; Hashemi, S.J. Corrosion inhibition of mild steel in $1 \mathrm{M} \mathrm{HCl}$ solution by henna extract: A comparative study of the inhibition by henna and its constituents (Lawsone, Gallic acid, $\alpha$-d-Glucose and Tannic acid). Corros. Sci. 2009, 51, 1935-1949, https://doi.org/10.1016/j.corsci.2009.05.024.

12. Boumhara, K.; Harhar, H.; Tabyaoui, M.; Bellaouchou, A.; Guenbour, A.; Zarrouk, A. Corrosion Inhibition of Mild Steel in 0.5 M H2SO4 Solution by Artemisia herba-alba Oil. J. Bio- Tribo-Corrosion 2019, 5, 1-9, https://doi.org/10.1007/s40735-018-0202-8.

13. Chatoui, K.; Echihi, S.; Harhar, H.; Zarrouk, A.; Tabyaoui, M. Chatoui et al An investigation of carbon steel corrosion inhibition in $1 \mathrm{M} \mathrm{HCl}$ by Lepidium sativum oil as green inhibitor. J. Mater. Environ. Sci 2018, 9 , 1212-1223, https://doi.org/10.26872/jmes.2017.9.

14. Abdallah, M.; Altass, H.M.; AL Jahdaly, B.A.; Salem, M.M. Some natural aqueous extracts of plants as green inhibitor for carbon steel corrosion in $0.5 \mathrm{M}$ sulfuric acid. Green Chem. Lett. Rev. 2018, 11, 189-196.

15. Abdallah, M.; Altass, H.M.; Al-Gorair, A.S.; Al-Fahemi, J.H.; Jahdaly, B.A.A.L.; Soliman, K.A. Natural nutmeg oil as a green corrosion inhibitor for carbon steel in $1.0 \mathrm{M} \mathrm{HCl}$ solution: Chemical, electrochemical, and computational methods. J. Mol. Liq. 2021, 323, 115036, https://doi.org/10.1016/j.molliq.2020.115036.

16. Ahamad, I.; Prasad, R.; Quraishi, M.A. Thermodynamic, electrochemical and quantum chemical investigation of some Schiff bases as corrosion inhibitors for mild steel in hydrochloric acid solutions. Corros. Sci. 2010, 52, 933-942, https://doi.org/10.1016/j.corsci.2009.11.016.

17. Mishrif, M.R.; Noor El-Din, M.R.; Khamis, E.A. Utilization of ethoxylated pentamine oleamide as new Gemini surfactants for corrosion inhibition effectiveness in $1 \mathrm{M} \mathrm{HCl}$ solution. Egypt. J. Pet. 2018, 27, 13571370, https://doi.org/10.1016/j.ejpe.2018.09.004. 
18. Olawale, O.; Bello, J.O.; Ogunsemi, B.T.; Uchella, U.C.; Oluyori, A.P.; Oladejo, N.K. Optimization of chicken nail extracts as corrosion inhibitor on mild steel in 2M H2SO4. Heliyon 2019, 5, e02821, https://doi.org/10.1016/j.heliyon.2019.e02821.

19. Al-Baghdadi, S.B.; Hashim, F.G.; Salam, A.Q.; Abed, T.K.; Gaaz, T.S.; Al-Amiery, A.A.; Kadhum, A.A.H.; Reda, K.S.; Ahmed, W.K. Synthesis and corrosion inhibition application of NATN on mild steel surface in acidic media complemented with DFT studies. Results Phys. 2018, 8, 1178-1184, https://doi.org/10.1016/j.rinp.2018.02.007.

20. Ali, N.; Fulazzaky, M.A. The empirical prediction of weight change and corrosion rate of low-carbon steel. Heliyon 2020, 6, e05050, https://doi.org/10.1016/j.heliyon.2020.e05050.

21. Cotting, F.; Aoki, I.V. Octylsilanol and Ce(III) ions - Alternative corrosion inhibitors for carbon steel in chloride neutral solutions. J. Mater. Res. Technol. 2020, 9, 8723-8734, https://doi.org/10.1016/j.jmrt.2020.06.011.

22. Khadom, A.A.; Abd, A.N.; Ahmed, N.A. Xanthium strumarium leaves extracts as a friendly corrosion inhibitor of low carbon steel in hydrochloric acid: Kinetics and mathematical studies. South African J. Chem. Eng. 2018, 25, 13-21, https://doi.org/10.1016/j.sajce.2017.11.002.

23. Alibakhshi, E.; Ramezanzadeh, M.; Bahlakeh, G.; Ramezanzadeh, B.; Mahdavian, M.; Motamedi, M. Glycyrrhiza glabra leaves extract as a green corrosion inhibitor for mild steel in $1 \mathrm{M}$ hydrochloric acid solution: Experimental, molecular dynamics, Monte Carlo and quantum mechanics study. J. Mol. Liq. 2018, 255, 185-198, https://doi.org/10.1016/j.molliq.2018.01.144.

24. Hassannejad, H.; Nouri, A. Sunflower seed hull extract as a novel green corrosion inhibitor for mild steel in HCl solution. J. Mol. Liq. 2018, 254, 377-382, https://doi.org/10.1016/j.molliq.2018.01.142.

25. Zarrouk, A.; Hammouti, B.; Lakhlifi, T.; Traisnel, M.; Vezin, H.; Bentiss, F. New 1H-pyrrole-2,5-dione derivatives as efficient organic inhibitors of carbon steel corrosion in hydrochloric acid medium: Electrochemical, XPS and DFT studies. Corros. Sci. 2015, 90, 572-584, https://doi.org/10.1016/j.corsci.2014.10.052.

26. Hassannejad, H.; Barati, A.; Nouri, A. The use of nanoemulsion-based strategies to improve corrosion inhibition efficiency of Thyme-based inhibitor. J. Mol. Liq. 2019, 296, 112110, https://doi.org/10.1016/j.molliq.2019.112110.

27. Anadebe, V.C.; Onukwuli, O.D.; Omotioma, M.; Okafor, N.A. Experimental, theoretical modeling and optimization of inhibition efficiency of pigeon pea leaf extract as anti-corrosion agent of mild steel in acid environment. Mater. Chem. Phys. 2019, 233, 120-132, https://doi.org/10.1016/j.matchemphys.2019.05.033.

28. El-Hashemy, M.A.; Sallam, A. The inhibitive action of Calendula officinalis flower heads extract for mild steel corrosion in $1 \mathrm{M} \mathrm{HCl}$ solution. J. Mater. Res. Technol. 2020, 9, 13509-13523, https://doi.org/10.1016/j.jmrt.2020.09.078.

29. Ferhat, M.; Benchettara, A.; Amara, S.E.; Najjar, D. Corrosion behaviour of Fe-C alloys in a Sulfuric Medium. Environ. Sci 2014, 5, 1059-1068.

30. El Faydy, M.; Touir, R.; Ebn Touhami, M.; Zarrouk, A.; Jama, C.; Lakhrissi, B.; Olasunkanmi, L.O.; Ebenso, E.E.; Bentiss, F. Corrosion inhibition performance of newly synthesized 5-alkoxymethyl-8-hydroxyquinoline derivatives for carbon steel in $1 \mathrm{M} \mathrm{HCl}$ solution: Experimental, DFT and Monte Carlo simulation studies. Phys. Chem. Chem. Phys. 2018, 20, 20167-20187, https://doi.org/10.1039/c8cp03226b.

31. Zarrok, H.; Zarrouk, A.; Salghi, R.; Oudda, H.; Hammouti, B.; Ebn Touhami, M.; Bouachrinee, M.; Pucci, O.H. A Combined Experimental and Theoretical Study on the Corrosion Inhibition and Adsorption Behaviour of Quinoxaline Derivative During Carbon Steel Corrosion in Hydrochloric Acid. Port. Electrochim. Acta 2012, 30, 405-417.

32. Khadraoui, A.; Khelifa, A.; Hadjmeliani, M.; Mehdaoui, R.; Hachama, K.; Tidu, A.; Azari, Z.; Obot, I.B.; Zarrouk, A. Extraction, characterization and anti-corrosion activity of Mentha pulegium oil: Weight loss, electrochemical, thermodynamic and surface studies. J. Mol. Liq. 2016, 216, 724-731, https://doi.org/10.1016/j.molliq.2016.02.005.

33. El Faydy, M.; Lakhrissi, B.; Jama, C.; Zarrouk, A.; Olasunkanmi, L.O.; Ebenso, E.E.; Bentiss, F. Electrochemical, surface and computational studies on the inhibition performance of some newly synthesized 8-hydroxyquinoline derivatives containing benzimidazole moiety against the corrosion of carbon steel in phosphoric acid environment. J. Mater. Res. Technol. 2020, 9(1), 727-748, https://doi.org/10.1016/j.jmrt.2019.11.014.

34. Zhao, A.; Sun, H.; Chen, L.; Huang, Y.; Lu, X.; Mu, B.; Gao, H.; Wang, S.; Singh, A. Electrochemical studies of bitter gourd (Momordica charantia) fruits as ecofriendly corrosion inhibitor for mild steel in $1 \mathrm{M} \mathrm{HCl}$ solution. Int. J. Electrochem. Sci. 2019, 14, 6814-6825, https://doi.org/10.20964/2019.07.75.

35. Cherrak, K.; Benhiba, F.; Sebbar, N.K.; Essassi, E.M.; Taleb, M.; Zarrouk, A.; Dafali, A. Corrosion inhibition of mild steel by new Benzothiazine derivative in a hydrochloric acid solution: Experimental evaluation and theoretical calculations. Chem. Data Collect. 2019, 22, 100252, https://doi.org/10.1016/j.cdc.2019.100252.

36. Saxena, A.; Thakur, K.K.; Bhardwaj, N. Electrochemical studies and surface examination of low carbon steel by applying the extract of Musa acuminata. Surf. Interfaces 2020, 18, 100436, https://doi.org/10.1016/j.surfin.2020.100436.

37. Kerroum, Y.; Guenbour, A.; Bellaouchou, A.; Idrissi, H.; Garcia-Anton, J.; Zarrouk, A. Chemical and 
Physical Effects of Fluoride on the Corrosion of Austenitic Stainless Steel in Polluted Phosphoric Acid. $J$. Bio- Tribo-Corrosion 2019, 5, 68, https://doi.org/10.1007/s40735-019-0261-5.

38. Zhao, Y.; Pan, T.; Yu, X.; Chen, D. Corrosion inhibition efficiency of triethanolammonium dodecylbenzene sulfonate on Q235 carbon steel in simulated concrete pore solution. Corros. Sci. 2019, 158, 108097, https://doi.org/10.1016/j.corsci.2019.108097.

39. Khattabi, M.; Benhiba, F.; Tabti, S.; Djedouani, A.; El Assyry, A.; Touzani, R.; Warad, I.; Oudda, H.; Zarrouk, A. Performance and computational studies of two soluble pyran derivatives as corrosion inhibitors for mild steel in HCl. J. Mol. Struct. 2019, 1196, 231-244, https://doi.org/10.1016/j.molstruc.2019.06.070.

40. Jessima, S.J.H.M.; Berisha, A.; Srikandan, S.S.; Subhashini, S. Preparation, characterization, and evaluation of corrosion inhibition efficiency of sodium lauryl sulfate modified chitosan for mild steel in the acid pickling process. J. Mol. Liq. 2020, 320, 114382, https://doi.org/10.1016/j.molliq.2020.114382.

41. Hosseini, M.G.; Ehteshamzadeh, M.; Shahrabi, T. Protection of mild steel corrosion with Schiff bases in 0.5 M H2SO4 solution. Electrochim. Acta 2007, 52, 3680-3685, https://doi.org/10.1016/j.electacta.2006.10.041.

42. Hsu, C.H.; Mansfeld, F. Concernng the conversion of the constant phase element parameter Y0 into a capacitance. Corrosion 2001, 57, 747-748, https://doi.org/10.5006/1.3280607.

43. Gao, M.; Zhang, J.; Liu, Q.; Li, J.; Zhang, R.; Chen, G. Effect of the alkyl chain of quaternary ammonium cationic surfactants on corrosion inhibition in hydrochloric acid solution. Comptes Rendus Chim. 2019, 22, 355-362, https://doi.org/10.1016/j.crci.2019.03.006.

44. El Faydy, M.; Lakhrissi, B.; Jama, C.; Zarrouk, A.; Olasunkanmi, L.O.; Ebenso, E.E.; Bentiss, F. Electrochemical, surface and computational studies on the inhibition performance of some newly synthesized 8-hydroxyquinoline derivatives containing benzimidazole moiety against the corrosion of carbon steel in phosphoric acid environment. J. Mater. Res. Technol. 2020, 9, 727-748, https://doi.org/10.1016/j.jmrt.2019.11.014.

45. About, H.; El Faydy, M.; Benhiba, F.; Kerroum, Y.; Kaichouh, G.; Oudda, H.; Guenbour, A.; Lakhrissi, B.; Warad, I.; Zarrouk, A. Experimental and empirical assessment of two new 8-hydroxyquinoline analogs as effective corrosion inhibitor for $\mathrm{C} 22 \mathrm{E}$ steel in $1 \mathrm{M} \mathrm{HCl}$. J. Mol. Liq. 2020, 114644, https://doi.org/10.1016/j.molliq.2020.114644.

46. El Faydy, M.; Benhiba, F.; Berisha, A.; Kerroum, Y.; Jama, C.; Lakhrissi, B.; Guenbour, A.; Warad, I.; Zarrouk, A. An experimental-coupled empirical investigation on the corrosion inhibitory action of 7-alkyl-8Hydroxyquinolines on $\mathrm{C} 35 \mathrm{E}$ steel in $\mathrm{HCl}$ electrolyte. J. Mol. Liq. 2020, 317, 113973, https://doi.org/10.1016/j.molliq.2020.113973.

47. Nabah, R.; Benhiba, F.; Ramli, Y.; Ouakki, M.; Cherkaoui, M.; Oudda, H.; Touir, R.; Warad, I.; Zarrouk, A. Corrosion Inhibition Study of 5, 5-diphenylimidazolidine2, 4-dione for Mild Steel Corrosion in $1 \mathrm{M} \mathrm{HCl}$ Solution: Experimental, Theoretical Computational and Monte Carlo Simulations Studies. Anal. Bioanal. Electrochem. 2018, 10, 1375-1398.

48. Mu, G.N.; Li, X.; Li, F. Synergistic inhibition between o-phenanthroline and chloride ion on cold rolled steel corrosion in phosphoric acid. Mater. Chem. Phys. 2004, 86, 59-68, https://doi.org/10.1016/j.matchemphys.2004.01.041.

49. Morad, M.S.; El-Dean, A.M.K. 2,2'-Dithiobis(3-cyano-4,6-dimethylpyridine): A new class of acid corrosion inhibitors for mild steel. Corros. Sci. 2006, 48, 3398-3412, https://doi.org/10.1016/j.corsci.2005.12.006.

50. Boujakhrout, A.; Hamdani, I.; Chahboun, N.; Bouyanzer, A.; Santana, R. V.; Zarrouk, A. Antioxidant activity and corrosion inhibitive behavior of Garcinia cola seeds on mild steel in hydrochloric medium. J. Mater. Environ. Sci. 2015.

51. Salhi, A.; Hamdani, I.; Bouyanzer, A.; Chahboun, N.; Amhamdi, H.; Warad, I.; Hammouti, B.; Bentiss, F.; Zarrouk, A. Phytochemical analysis, antioxidant and anticorrosive activities of thymus algeriensis extracts. Anal. Bioanal. Electrochem. 2018.

52. Faustin, M.; Maciuk, A.; Salvin, P.; Roos, C.; Lebrini, M. Corrosion inhibition of C38 steel by alkaloids extract of Geissospermum laeve in $1 \mathrm{M}$ hydrochloric acid: Electrochemical and phytochemical studies. Corros. Sci. 2015, https://doi.org/10.1016/j.corsci.2014.12.005.

53. El Hamdani, N.; Fdil, R.; Tourabi, M.; Jama, C.; Bentiss, F. Alkaloids extract of Retama monosperma (L.) Boiss. seeds used as novel eco-friendly inhibitor for carbon steel corrosion in $1 \mathrm{M} \mathrm{HCl}$ solution: Electrochemical and surface studies. Appl. Surf. Sci. 2015, https://doi.org/10.1016/j.apsusc.2015.09.159.

54. Canton, L.C.; Souza Júnior, I.G. de; Silva, L.S.; Marques Júnior, J.; Costa, A.C.S. da Identification and quantification of iron oxides by diffuse reflectance spectroscopy with Praying Mantis accessory and integration sphere. CATENA 2021, 196, 104899, https://doi.org/10.1016/J.CATENA.2020.104899.

55. Leone, N.; Mercurio, M.; Grilli, E.; 2011, Undefined Potential of vis-NIR reflectance spectroscopy for the mineralogical characterization of synthetic gleys: a preliminary investigation. books.google.com.

56. Coblinski, J.A.; Inda, A.V.; Demattê, J.A.M.; Dotto, A.C.; Gholizadeh, A.; Giasson, É. Identification of minerals in subtropical soils with different textural classes by VIS-NIR-SWIR reflectance spectroscopy. CATENA 2021, 203, 105334, https://doi.org/10.1016/j.catena.2021.105334.

57. Kerroum, Y.; Skal, S.; Guenbour, A.; Bellaouchou, A.; Tabyaoui, M.; Zarrouk, A.; Garcia Anton, J. Effect of fluoride on corrosion behavior of UNS N08904 stainless steel in polluted phosphoric acid. J. Mol. Liq. 2018, https://doi.org/10.1016/j.molliq.2018.06.008. 
58. Kerroum, Y.; Guenbour, A.; Bellaouchou, A.; Idrissi, H.; García-Antón, J.; Zarrouk, A. The corrosion of white cast iron in polluted phosphoric acid medium contains fluoride ions. Anal. Bioanal. Electrochem. 2019, 11.

59. Kerroum, Y.; Skal, S.; Guenbour, A.; Bellaouchou, A.; Boulif, R.; Anton, J.G.; Zarrouk, A. A novel investigation on the cast iron corrosion in polluted phosphoric acid. Surfaces and Interfaces 2020, 19, 100481, https://doi.org/10.1016/J.SURFIN.2020.100481.

60. Abderrazak, H.; Dachraoui, M.; Lendl, B. A novel flow injection procedure for determination of phosphate in industrial raw phosphoric acid. Analyst 2000, 125, 1211-1213, https://doi.org/10.1039/b001208o. 